\title{
Unilateral morning glory disc anomaly in a patient with prenatal Zika virus exposure
}

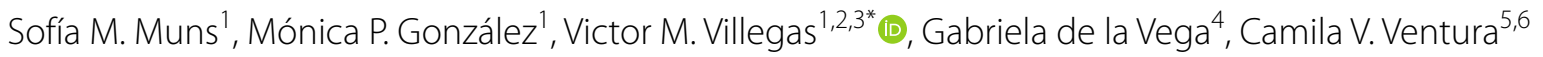
and Audina M. Berrocal ${ }^{2}$

\begin{abstract}
Background: To report a case of morning glory disc anomaly (MGDA) in a pediatric patient with prenatal Zika virus (ZIKV) exposure.

Case presentation: A 3-year-old male with prenatal exposure to ZIKV, confirmed by real-time polymerase chain reaction testing during the second trimester of pregnancy, was evaluated due to visual loss. Physical examination was remarkable for unilateral MGDA. Neuroimaging showed a base of skull encephalocele through the floor of the sella and callosal dysgenesis.
\end{abstract}

Conclusions: This is the first report to suggest an association between prenatal ZIKV exposure and MGDA. Prenatal ZIKV exposure may be associated to a wider pathologic spectrum than previously reported.

Keywords: Zika virus, Morning glory disc anomaly, Optic disc, Excavated disc anomaly, Coloboma

\section{Introduction}

Morning glory disc anomaly (MGDA) is a rare congenital anomaly of the optic disc and peripapillary retina $[1$, 2]. The prevalence of MGDA has been estimated to be approximately 2.6/100,000 [3]. Characteristic findings include an enlarged optic disc with a central funnelshaped excavation, a hypopigmented central tuft of glial tissue, peripapillary chorioretinal atrophy, and radial spoke-like vascular pattern $[1,2,4,5]$. MGDA is sporadic, exhibits female predominance, and is typically unilateral $[1,4,6,7]$. MGDA has also been associated with midline craniofacial defects $[1,6]$. Central visual acuity may be normal or decreased, depending on the extent of the disease [7].

The Zika virus (ZIKV) is a single-stranded RNA arbovirus that developed into a global health concern during 2016 and affected approximately 1.5 million people

\footnotetext{
*Correspondence: v.villegas@villegasmd.com

1 Department of Ophthalmology, University of Puerto Rico, Medical Sciences Campus, San Juan, PR 00936-5067, USA

Full list of author information is available at the end of the article
}

in South and Central America $[8,9]$. The virus is mainly transmitted by the Aedes aegypti mosquito $[8,9]$. However, vertical transmission has also been described [10]. The exposure to ZIKV during pregnancy has been associated to a wide variety of birth defects, including the congenital Zika syndrome (CZS) [10]. CZS is characterized by microcephaly, intracranial calcifications, decrease brain volume, ocular defects, congenital contractures, and hypertonia soon after birth [10, 11] Reported ophthalmologic manifestations include congenital cataracts, congenital glaucoma, lens subluxation, iris coloboma, microphthalmia, chorioretinal atrophy, pigment mottling, optic nerve anomalies, retinal vessels attenuation, and strabismus [9, 12-18]. Intracranial and intraocular anomalies may be present symmetrically or asymmetrically.

The reported prevalence of optic nerve disease among patients in Brazil with prenatal ZKV exposure has been estimated to be $17-32 \%$ [13-17]. These abnormalities include optic disc coloboma, hypoplasia, atrophy, pallor, and increased cup-to-disc ratio [9, 10, 13-17]. In this 
report, we describe the clinical features associated to the first case of MGDA following prenatal ZIKV exposure.

\section{Case report}

A 3-year-old male child with a previous medical history of strabismus and cleft lip was referred to our clinics due to an anomalous optic disc and visual loss. Perinatal history revealed that during the second trimester of pregnancy the mother developed a generalized maculopapular rash. The mother denied having any other symptoms including headache, fever, conjunctivitis, arthralgia, or myalgia. Due to her symptoms, the mother underwent a real-time polymerase chain reaction (RT-PCR) test for ZIKV with positive results. Postnatal history was remarkable for a 4 day hospitalization at the neonatal intensive care unit (NICU) due to hyperbilirubinemia treated with phototherapy. Previous ocular history was remarkable for decreased visual acuity in the right eye (OD) with sensory exotropia diagnosed at 11 months of age. Strabismus surgery had been undertaken after unsuccessful occlusion therapy with excellent anatomical outcomes.

A complete ophthalmological exam was performed. Best-corrected visual acuity was 20/200 OD and 20/20 in the left eye (OS). Intraocular pressure was normotensive in both eyes (OU). No nystagmus was present. Extraocular muscle ductions were full, but a small angle exotropia was present OD. Pupils were equally round and with an afferent pupillary defect OD. The anterior segment was unremarkable OU.

Posterior segment examination showed a centrally excavated optic disc with associated hypopigmented glial tuft, peripapillary chorioretinal atrophy, and radial spoke-like vascular pattern consistent with MGDA OD (Fig. 1). No foveal reflex was present OD. The OS posterior segment was unremarkable (Fig. 1).
Magnetic resonance imaging (MRI) and computed tomography $(\mathrm{CT})$ were performed and were remarkable for a base of skull encephalocele and callosal dysgenesis. The pituitary gland, infundibulum and optic chiasm were not well visualized raising concern for other associated midline developmental abnormalities (Fig. 2).

\section{Discussion and conclusions}

MGDA is part of a spectrum of diseases affecting the optic disc known as excavated optic disc anomalies, which also include peripapillary staphyloma, optic disc coloboma, optic disc pit, megalopapilla, and optic disc dysplasia [18]. The pathophysiological mechanisms leading to the spectrum of excavated optic disc anomalies continue to be incompletely understood $[18,19]$. We report the first case of MGDA after confirmed prenatal ZIKV exposure. It is possible that ZIKV infection may alter intrauterine optic nerve development and lead to MGDA.

MGDA is a non-progressive congenital anomaly of the optic disc that has been associated with other ocular anomalies including strabismus, microphthalmia, amblyopia, leukocoria, nystagmus, eyelid hemangioma, and visual field defects [1, 2, 4-7, 19]. Complex retinal detachments and choroidal neovascularization may develop in eyes with MGDA [4, 19]. Systemic cerebral and craniofacial malformations may be present including frontonasal dysplasia, basal encephalocele, pituitary insufficiency, agenesis of the corpus callosum, hypertelorism, cleft lip, cleft palate, and cerebrovascular anomalies $[1,2,6,19]$. Therefore, neuroimaging should be performed in all cases. In our case, neuroimaging showed a base of skull encephalocele and callosal dysgenesis. The
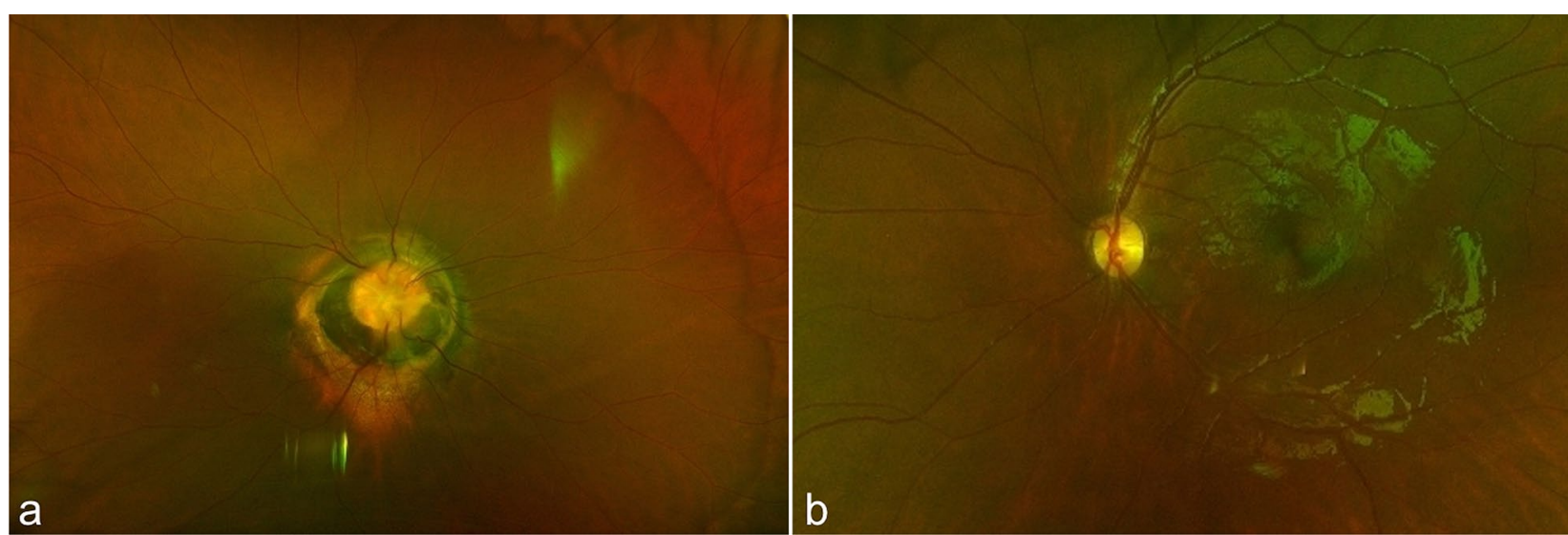

Fig. 1 Color fundus photography of both eyes. The right optic disc (a) has a central funnel-shaped excavation, gliosis, peripapillary atrophy, and a radial spoke-like vascular pattern. The left optic disc $(\mathbf{b})$ is normal 


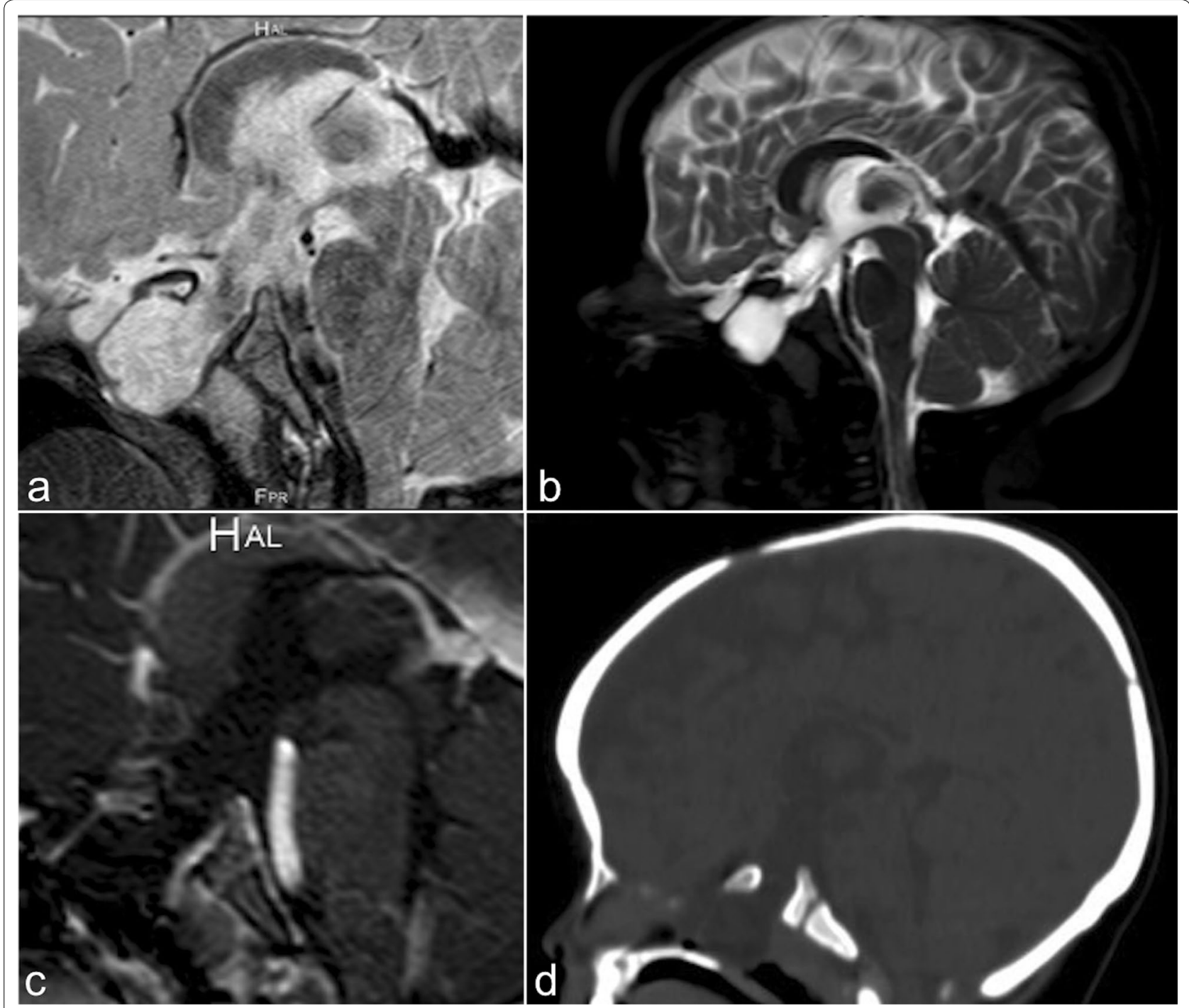

Fig. 2 Brain magnetic resonance imaging and computerized tomography. Sagittal T2 (a and b), sagittal post-contrast T1 (c) weighted images, and sagittal non-contrast CT (d) of the brain through midline demonstrate a bony defect at the floor of the sella with herniation of cerebrospinal fluid through the defect into the sphenoid sinuses consistent with a base of skull encephalocele. There is also evidence of absence of the distal body, splenium, and rostrum of the corpus callosum consistent with callosal dysgenesis. The pituitary gland, infundibulum, and optic chiasm were not well visualized raising concern for other associated midline developmental abnormalities

midline brain structures including the pituitary gland, infundibulum, and optic chiasm were not well visualized.

The ZIKV may have a broad spectrum of ocular manifestations. The most commonly affected ocular structures are the retina and optic nerve [10]. Studies that have evaluated infants with prenatal ZIKV exposure have reported optic disc anomalies in $17-32 \%$ of subjects [13-17]. The spectrum of optic disc anomalies reported included optic nerve hypoplasia, optic disc coloboma, increased cup-to-disc ratio, and optic nerve atrophy $[9$, 10, 13-17]. Although bilateral optic disc involvement is most commonly found, unilateral optic disc findings have been reported in up to $30 \%$ of cases [13-17]. Additionally, while ocular involvement most commonly occurs among patients with microcephaly, previous studies have described optic disc anomalies among patients without microcephaly [14-17]. Interestingly, no reports of MGDA in children with prenatal ZIKV exposure have been documented.

Van den Pol and associates [20] have theorized that after ZIKV is vertically transmitted, it may invade the cortical progenitor cells inside the fetal brain. The virus may then infect, via axonal transport, other parts of the visual system including the retina, optic chiasm, 
suprachiasmatic nucleus, and superior colliculus [9, 20]. Some histologic studies have suggested that glial cells within the optic chiasm and optic tract may be an important target of the ZIKV [9, 20]. To support this hypothesis, Fernandez et al. performed a histopathological evaluation of four deceased fetuses and isolated ZIKV from the optic nerve, neural retina, and choroid [21]. The intracranial anomalies that have been associated to MGDA overlap with those reported in some cases of CZS. It is possible that early glial cell dysfunction inside the optic nerve may lead to MGDA. Future studies may determine the exact mechanisms that lead to MGDA.

To our knowledge, this is the first study to report a case of MGDA in a patient with prenatal ZIKV exposure. The rarity MGDA may explain the lack of previous reports among children with prenatal ZIKV exposure [22, 23]. Although our report cannot demonstrate a causal relationship between prenatal ZIKV exposure and MGDA, their association should be explored in future research studies. This report suggests that prenatal exposure to ZIKV may lead to a wider pathological spectrum than previously described.

\section{Abbreviations}

ZIKV: Zika virus; CT: Computerized tomography; MRI: Magnetic resonance imaging; MGDA: Morning glory disc anomaly; RT-PCR: Real time polymerase chain reaction; OD: Right eye; OS: Left eye; OU: Both eyes; CZS: Congenital Zika syndrome.

\section{Acknowledgements}

Not applicable.

\section{Authors' contributions}

SMM, MPG, GV and VMV collected the data and prepared the manuscript. CVV, $A M B$ and VMV performed critical revision of the article. All authors read and approved the final manuscript.

\section{Funding}

Supported in part by the National Eye Institute Center Core Grant (P30EY014801), and an unrestricted grant to the University of Miami from Research to Prevent Blindness, Inc. (New York, NY).

\section{Availability of data and materials}

All data generated or analyzed during this study are included in this manuscript.

\section{Ethics approval and consent to participate}

Informed consent for publication of clinical details and/or images was obtained from the patient. Ethics approval is not applicable.

\section{Consent for publication}

Written informed consent was acquired.

\section{Competing interests}

The authors declare that they have no competing interests.

\section{Author details}

${ }^{1}$ Department of Ophthalmology, University of Puerto Rico, Medical Sciences Campus, San Juan, PR 00936-5067, USA. ${ }^{2}$ Bascom Palmer Eye Institute, University of Miami Miller School of Medicine, Miami, FL 33136, USA. ${ }^{3}$ Department of Surgery, Ponce Health Sciences University, Ponce, PR 00732-7004, USA.

${ }^{4}$ Department of Radiology, HIMA San Pablo Hospital, Caguas, PR 00726-4980,
USA. ${ }^{5}$ Department of Ophthalmology, Altino Ventura Foundation, Recife, Brazil. ${ }^{6}$ Department of Ophthalmology, HOPE Eye Hospital, Recife, Brazil.

Received: 23 March 2020 Accepted: 25 July 2020

Published online: 01 August 2020

References

1. Lenhart PD, Lambert SR, Newman NJ, Biousse V, Atkinson DS Jr, Traboulsi El, Hutchinson AK. Intracranial vascular anomalies in patients with morning glory disk anomaly. Am J Ophthalmol. 2006;142(4):644-50.

2. Kinori M, Smiley NP, Zeid JL. Morning glory disc anomaly and ipsilateral sporadic optic pathway glioma. Am J Ophthalmol Case Rep. 2018:10:16-7.

3. Ceynowa DJ, Wickström R, Olsson M, Ek U, Eriksson U, Kristoffersen Wiberg M, Teär Fahnehjelm K. Morning glory disc anomaly in childhood population-based study. Acta Ophthalmol. 2015;93:626-34.

4. Ahuja AA, Adenuga OO, Kumar J, Kannan NB, Ramasamy K. Retinal detachment in morning glory disc anomaly: prevalence and outcome of treatment. Niger J Ophthalmol. 2018;26(2):128-32.

5. Fei P, Zhang Q, Li J, Zhao P. Clinical characteristics and treatment of 22 eyes of morning glory syndrome associated with persistent hyperplastic primary vitreous. Br J Ophthalmol. 2013;97(10):1262-7.

6. Koerner JC, Sweeney J, Rheeman C, Kenning TJ. Delayed presentation of morning glory disc anomaly and transsphenoidal encephalocele: a management dilemma. Neuroophthalmology. 2018;43(2):95-101.

7. Georgalas I, Spyropoulos D, Paraskevopoulos T, Rotsos T. Morning glory disc anomaly in a child with esotropia. J Pediatr. 2018;203:458-458.

8. Slavov SN, Otaguiri KK, Kashima S, Covas DT. Overview of zika virus (ZIKV) infection in regards to the Brazilian epidemic. Braz J Med Biol Res. 2016:49(5):e5420.

9. Ventura CV, Ventura Filho MC, Ventura LO. Ocular manifestations and visual outcome in children with congenital Zika syndrome. Top Magn Reson Imaging. 2019;28(1):23-7.

10. Moore CA, Staples JE, Dobyns WB, et al. Characterizing the pattern of anomalies in congenital Zika syndrome for pediatric clinicians. JAMA Pediatr. 2017;171(3):288-95.

11. Fitzgerald B, Boyle C, Honein MA. Birth defects potentially related to Zika virus infection during pregnancy in the United States. JAMA. 2018;319(12):1195-6.

12. Ventura CV, Maia M, Bravo-Filho V, Gois AL, Belfort R Jr. Zika virus in Brazil and macular atrophy in a child with microcephaly. Lancet. 2016;387(10015):228

13. Ventura CV, Maia M, Travassos SB, et al. Risk factors associated with the ophthalmoscopic findings identified in infants with presumed Zika virus congenital infection. JAMA Ophthalmol. 2016;134(8):912-8.

14. Tsui I, Moreira MEL, Rossetto JD, Vasconcelos Z, Gaw SL, Neves LM, Zin $\mathrm{OA}$, et al. Eye findings in infants with suspected or confirmed antenatal Zika exposure. Pediatrics. 2018;142(4):e20181104.

15. Yepez JB, Murati FA, Pettito M, Peñaranda CF, de Yepez J, Maestre G, Arevalo JF, et al. Ophthalmic manifestations of congenital Zika syndrome in Colombia and Venezuela. JAMA Ophthalmol. 2017; 135(5):440-5.

16. Zin AA, Tsui I, Rossetto J, et al. Screening criteria for ophthalmic manifestations of congenital Zika virus infection. JAMA Pediatr. 2017;171(9):847-54.

17. Verçosa I, Carneiro P, Verçosa R, Girão R, Ribeiro EM, Pessoa A, et al. The visual system in infants with microcephaly related to presumed congenital Zika syndrome. J AAPOS. 2017;21(4):300-4.

18. Ganesh A. Cavitary anomalies of the optic disc: different entities or part of a single spectrum of disease? Oman J Ophthalmol. 2014;7(2):53-4.

19. Lee BJ, Traboulsi El. Update on the morning glory disc anomaly. Ophthalmic Genet. 2008;29(2):47-52.

20. van den Pol AN, Mao G, Yang Y, Ornaghi S, Davis JN. Zika virus targeting in the developing brain. J Neurosci. 2017;37(8):2161-75.

21. Fernandez MP, Saad EP, Martinez MO, Corchuelo S, Reyes MM, Herrera MJ, et al. Ocular histopathologic features of congenital Zika syndrome. JAMA Ophthalmol. 2017;135(11):1163-9. 
22. National Institutes of Health. Morning glory syndrome; 2017. https:// rarediseases.info.nih.gov/diseases/13354/morning-glory-syndrome. Accessed 7 July 2020

23. American Academy of Ophthalmology. Morning glory syndrome; 2015. https://www.aao.org/pediatric-center-detail/neuro-ophthalmologymorning-glory-syndrome. Accessed 7 July 2020.

\section{Publisher's Note}

Springer Nature remains neutral with regard to jurisdictional claims in published maps and institutional affiliations.
Ready to submit your research? Choose BMC and benefit from:

- fast, convenient online submission

- thorough peer review by experienced researchers in your field

- rapid publication on acceptance

- support for research data, including large and complex data types

- gold Open Access which fosters wider collaboration and increased citations

- maximum visibility for your research: over 100M website views per year

At BMC, research is always in progress.

Learn more biomedcentral.com/submissions 